\title{
Equilíbrio fiscal e política econômica keynesiana
}

\author{
Fernando J . Cardim de Carvalho*
}

Resumo: Críticos conservadores do keynesianismo sempre focalizaram suas restrições na suposta carta branca que Keynes teria dado ao estado para abandonar qualquer regra de disciplina sobre seus gastos, despreocupando-se com os possíveis impactos de persistentes déficits fiscais. Keynes realmente centrou suas preocupações na geração de níveis de demanda agregada que pudessem levar empresários a decidir oferecer o volume de empregos correspondente ao pleno emprego da força de trabalho da economia. Sua estratégia de política macroeconômica, porém, era muito mais sutil do que a simples aprovação da realização de déficitsfiscais. A visão de Keynes é apoiada, na verdade, em dois pilares: o primeiro, de que uma política de gastos expansionista não é necessariamente deficitária porque o próprio crescimento da renda leva a um aumento da arrecadação de impostos. Alem disso, o crescimento da renda leva também a um crescimento da poupança e, com ela, ao aumento da demanda por títulos, inclusive os de dívida pública, financiando-se assim de forma não inflacionária o déficitrestante. 0 segundo pilar é o efeito sobre expectativas empresariais do ativismo estatal que sinalizaria a manutenção de elevada demanda agregada e estimularia investimentos privados que poderiam mesmo tornar desnecessária a realização de gastos públicos mais amplos. Déficits fiscais emergeriam apenas quando esses impactos sobre expectativas, por alguma razão, não se materializassem.

Palavras-chave: Keynes, Macroeconomia Keynesiana, Política Fiscal.

Abstract: Conservative critics of Keynesianism always centered their critiques on the comfort Keynes supposedly gave to irresponsible governments, justifying the persistent occurrence of fiscal deficits. Keynes was in fact concerned with the inability of entrepreneurial economies to spontaneously generate adequate levels of aggregate demand. His policy strategy, however, was much subtler than that described by critics. The strategy relied on two pillars. The first was that expansionary fiscal policy operated through increasing public spending, not increasing deficits. Increased spending would expand income and, as a result, increase tax revenues. Besides, increasing income means also increasing savings and increasing demand for securities, including those issued by governments to finance residual deficits. The second pillar of his policy strategy was that the existence of activist governments, concerned with maintaining full employment would positively impact businessmen's expectations, inducing them to increase private investments, reducing thereby the need for actual fiscal spending. Deficits would result only in situations where this effect on expectations, for some reason, did not materialize.

* Professor Titular do Instituto de Economia da Universidade Federal do Rio de J aneiro. 0 apoio do CNPq e da Faperj (projeto Pronex) são aqui reconhecidos. 
Keyw ords: Keynes, Keynesian Macroeconomics, Fiscal Policy.

J EL Classification: E12; H30.

\section{Introdução}

A utilização do termo keynesianismo como identificador de uma certa doutrina com relação ao papel do estado na economia há muito ultrapassou as fronteiras do mundo acadêmico para ser incorporado ao vocabulário cotidiano de políticos, jornalistas, empresários, etc. Círculos acadêmicos, no entanto, identificam como cerne do keynesianismo algo diferente do que pensam jornalistas e líderes políticos. Para os primeiros, o keynesianismo (ou "modelo" keynesiano) é uma visão de economia que se apóia na idéia de preços (e salários) rígidos. Modelos keynesianos, portanto, seriam aqueles que descrevem a forma pela qual uma economia de mercado se ajusta a choques através de mudanças de "quantidades" ao invés de mudanças de preços, como as preconizadas pelas chamadas correntes clássicas (como os monetaristas de Milton Friedman ou, ainda mais notadamente, os "novos clássicos" de Robert Lucas).

0 debate político-jornalístico é menos sutil. De fato, nas suas formas mais vulgares, o keynesianismo é identificado com uma atitude de completa permissividade com relação à intervenção do Estado na economia. O keynesianismo daria ao Estado, virtualmente, uma permissão para matar, como nas novelas do agente 007. Estatização de empresas, elevados gastos públicos, elevados déficits públicos (o que não é a mesma coisa), excesso de regulação da atividade privada, estados de bem-estar excessivamente generosos, etc, seriam todos manifestações específicas de uma obscura filosofia subversiva, o keynesianismo, que se oporia às virtudes da ideologia liberal, que enfatizaria o esforço e a responsabilidade individuais, a auto-realização, a austeridade, a disciplina, etc. Alguns dos críticos mais precoces e mais insistentes do keynesianismo não se prenderam efetivamente a idéias ou proposições especificas de Keynes ou de seus seguidores. Para aqueles, a perversidade do keynesianismo estaria na legitimação da ação do Estado na economia, da idéia de intervenção. Assim, um proeminente economista conservador escreveu:

Em todos os tópicos ... a influência do keynesianismo sobre as políticas públicas foi lamentável. Políticas públicas identificaram incorretamente a barreira ao progresso econômico como sendo uma demanda agregada inadequada ou mal-estruturada, quando as próprias políticas definidas 
para resolver essa inadequação impuseram frequentemente impactos adversos sobre os cursos e recompensas de prover os insumos de que 0 crescimento econômico depende. A perseguição dessas políticas, alem disso, foi associada a uma presença sempre crescente do governo na economia, uma presenção que muito frequentemente ocultou ou distorceu os sinais de mercado e prejudicou as funções do mercado (TURE, 1985, p. 52).

Mesmo críticos menos ambiciosos (ou, talvez, melhor informados) tenderam a identificar o keynesianismo com uma proposição acima de todas as outras: a legitimidade do uso constante de déficits fiscais como arma de promoção da prosperidade econômica. Para esses comentaristas, a essência da política econômica keynesiana estaria na despreocupação com a geração continuada de déficits fiscais e, assim, na corrosão da noção de que a indisciplina fiscal possa ter qualquer efeito danoso sobre uma economia de mercado.

É uma curiosidade interessante da história das idéias contemporâneas verificar como ambas as noções de keynesianismo referidas, tanto a acadêmica quanto a político-jornalística, estão distantes do seu verdadeiro objeto. A crítica da identificação da abordagem de Keynes com a hipótese de rigidez de preços já foi feita de modo conclusivo na década dos 60 . A penas o amplo desconhecimento de grande parcela de economistas da história de sua própria disciplina mantém viva essa identificação. Mais compreensível, por outro lado, é a impropriedade da caracterização político-jornalística, por ser difundida entre grupos que não têm, geralmente, qualquer familiaridade com a obra de Keynes ou um conhecimento mais adequado da evolução da teoria e política macroeconômicas. No que se segue, apenas nos interessa esclarecer do que trata a política econômica keynesiana. ${ }^{1}$ Keynes, sem dúvida, acreditava na possibilidade do Estado cumprir um papel construtivo na promoção da prosperidade de economias de mercado. A sua abordagem da operação de uma economia capitalista, no entanto, era muito mais sofisticada e sutil do que a maioria de seus comentaristas (críticos ou simpáticos) parece ter percebido. Em particular, poucos perceberam que Keynes trata de gastos públicos, ao invés de déficits públicos, como instrumento de política macroeconômica. Poucos perceberam também suas preocupações, por um lado, com o estado da economia quando gastos fossem realizados (se em pleno emprego ou com desemprego e capacidade ociosa), ou com a capacidade dos mercados financeiros de financiar esses mesmos gastos públicos. O esclarecimento desses

1 A critica dos modelos chamados de keynesianos, baseados na hipótese de preços rígidos é facilmente encontrável. Pioneiros são os trabalhos de Leijonhufvud (1968) e Davidson (1972). 
aspectos e da noção de política econômica keynesiana é o intuito deste trabalho. Para tanto, além desta introdução, partiremos, na seção seguinte, da caracterização do problema a ser resolvido pela intervenção política, na visão de Keynes, qual seja, a possibilidade de que a demanda agregada seja insuficiente para induzir a ocupação da capacidade produtiva existente e a promoção do pleno emprego. $\mathrm{Na}$ seção 3 mostraremos como operaria a política fiscal na promoção da prosperidade econômica. A seção 4 explora os limites e os condicionantes da política fiscal. A seção 5 conclui o artigo.

\section{Problema}

No último capítulo de sua obra mais importante, A Teoria Geral do Emprego, J uros e Moeda (de agora em diante TG), Keynes afirma que há dois problemas centrais no capitalismo moderno. Um deles é a excessiva concentração de renda e riqueza que separa as classes sociais. A concentração excessiva contribuía para a dificuldade em sustentar o pleno emprego nas economias modernas, porque os ricos, que se beneficiavam da concentração, consumiam relativamente pouco em proporção à sua renda, enquanto os pobres, que consumiriam proporcionalmente mais, eram privados dessa possibilidade. 0 resultado era uma demanda total por bens de consumo mais fraca, que desestimulava a produção de bens de consumo e, indiretamente, a de bens de investimento. Alem disso, a concentração de renda excessiva solapava a legitimidade do capitalismo, pois criava grupos sociais que usufruíam da riqueza social sem terem contribuído para sua criação. ${ }^{2}$ A solução para esse problema, argumentava Keynes, repousava principalmente na promoção de mudanças institucionais, como a introdução de impostos progressivos, o imposto sobre capital e, especialmente, sobre heranças, etc. A política econômica poderia ajudar, mas não era particularmente potente para esse fim. ${ }^{3}$

o outro problema do capitalismo moderno era sua incapacidade de gerar continuamente o nível de demanda agregada capaz de alcançar ou, mais adequadamente, de sustentar o pleno emprego e a plena utilização da capacidade produtiva existente. Foi exatamente para explicar porque emergiam deficiências de demanda agregada que a GT foi escrita. Para Keynes, o combate ao desemprego exigiria uma postura ativa do Estado. A penas a disposição do Estado em intervir sempre que houvesse a perspectiva de insuficiência de demanda

2 Keynes já manifestava preocupação com a legitimidade da ordem social capitalista em The Economic Consequences of Peace, Keynes (1920).

$3 \mathrm{Na}$ verdade, a melhor contribuição da política macroeconômica ao bem estar social seria justamente sustentar o pleno emprego. Veja, por exemplo, Carvalho (2006). 
agregada poderia garantir a sustentação do pleno emprego. É neste contexto que emerge uma estratégia de política econômica caracteristicamente keynesiana.

É importante ressaltar a novidade que esta abordagem constituía quando concebida, nos anos 30 do século passado. 0 grande debate em torno às possibilidades de intervenção do Estado na economia até então voltava-se para a capacidade que governos teriam (ou não) de substituir os mercados privados na sua função alocativa. Esse era o debate conhecido como o do cálculo econômico em economias socialistas, que reuniu, em diferentes períodos, economistas como von Mises, Barone, Hayek, Lange, dentre outros. O ponto central desse debate era a capacidade de outros mecanismos, que não o mercado privado, organizarem de modo eficiente a atividade produtiva. A questão central era a de se um "ministério da produção" em uma economia socialista poderia gerar e processar o mesmo volume de informação que os mercados o fazem numa economia capitalista. Este debate levou a um quase-consenso em torno da idéia de que, embora fosse concebível teoricamente algum mecanismo que reunisse todas as informações necessárias para a decisão econômica eficiente, na prática não haveria qualquer possibilidade real de desenvolvê-lo. Deste modo, estabelecia-se a conclusão de que era melhor permitir que mercados operassem da forma mais livre possível (ressalvados, naturalmente, os casos de falhas de mercado) do que abrir espaço para a intervenção do Estado.

O problema de Keynes era completamente diferente. Em suas próprias palavras:

Se nossos controles centrais tiverem sucesso em estabelecer um volume de produto agregado que corresponda ao pleno emprego tanto quanto praticável, a teoria clássica volta a valer a partir desse ponto. Se supomos que o volume de produto é dado, isto é, determinado por forças que não fazem parte do esquema clássico de pensamento, então não haverá objeção a ser levantada contra a análise clássica da maneira em que o auto-interesse privado determinará em particular o que será produzido, em que proporçõesosfatores de produção serão combinados para produzi-lo, e como o valor do produto final será distribuído entre eles. [...] É na determinação do volume, não da direção, do emprego corrente que o sistema existente entrou em colapso (KEYNES, 1964, p. 378-9). ${ }^{4}$

4 A intervenção direta no sistema produtivo, portanto, é essencialmente estranha ao pensamento de Keynes, que abordava o problema de forma bastante pragmática. Como em suas discussões sobre o problema do carvão na Inglaterra dos anos 20, Keynes não alimentava posições apriorísticas a respeito da nacionalização de empresas. Seu programa de política econômica certamente nada tem a ver com iniciativas amplas de estatização ou nacionalização de empresas. Veja, para tanto, Carvalho (1997). 
Porque uma economia moderna não seria capaz de utilizar plenamente seus recursos disponíveis? Certamente não seria porque todas as necessidades humanas estivessem satisfeitas. $O$ desemprego que preocupava Keynes não era o concebido por economistas como Lucas, para quem ele nada mais representa que uma antecipação para o presente do lazer que os trabalhadores estariam usufruindo no futuro. Os desempregados de Lucas (e de Milton Friedman) abandonam os seus empregos porque preferem o lazer. Os desempregados de Keynes são demitidos pelos empregadores e para enfatizar este aspecto, Keynes denominou o fenômeno de desemprego involuntário. ${ }^{5}$ Se há necessidades a serem satisfeitas, porque recursos são deixados ociosos?

A resposta de Keynes é relativamente simples: porque uma economia empresarial (ou economia monetária, ambos os termos sendo preferidos por Keynes à expressão economia capitalista) não se organiza para satisfazer necessidades mas para atender demandas de mercado, isto é demandas que se apóiam em poder de compra. Uma economia empresarial, como a denominação sugere, é organizada por empresários, que criam empresas para reunir fatores de produção e desempenhar a atividade produtiva. Estas empresas, por sua vez, não existem para satisfazer as demandas de consumo de seus proprietários. Elas são arranjos criados para obter lucros, móvel e causa de sua existência. Empresas são máquinas de ampliação de riqueza, absorvendo valores (de insumos) para produzir valores (de produtos) ainda maiores. ${ }^{6}$

A produção de uma empresa só tem utilidade para ela, no entanto, quando vendida e, assim, transformada em dinheiro, de modo a permitir à empresa reiniciar o processo de produção de riquezas. Uma firma tecnicamente eficiente, mas incapaz de colocar no mercado sua produção a preços remuneradores irá falir tanto quanto uma empresa incapaz de produzir de uma maneira eficiente. O critério para medir o sucesso de uma empresa, portanto, é sua capacidade de obter lucro e este, por sua vez, depende da capacidade do empresário prever, o mais precisamente possível, que produtos serão demandados pelo mercado de modo a produzir aquilo que é vendável, não o que é redundante ou indesejado por compradores. 0 critério essencial é a satisfação da demanda solvável, isto é, o desejo por um bem, apoiado

5 Sobre a taxa natural de desemprego, veja, por exemplo, Tobin (1987, p. 315-6) e (2003, p. 153-5).

6 Sobre as características definidoras de uma economia monetária, veja Carvalho (1992, capítulo 3). 
na disponibilidade de poder de compra (isto é, de meios de pagamento com que pagar pelo produto).

Nestes termos, em uma economia empresarial o nível de atividades dependerá da expectativa de demanda dos empresários. Se essa expectativa é favorável, empresários empregarão trabalhadores para produzir e poderão, mesmo, adquirir novos equipamentos para ampliar a capacidade produtiva se a expectativa de demanda futura for forte (e durável) o suficiente para justificar a decisão de investir.

Esse arranjo produtivo mostrou-se extremamente poderoso. Nos seus melhores períodos, economias empresariais exibem uma capacidade de crescimento e de inovação inigualável por qualquer outra forma de organização da produção, como a disputa entre economias centralizadas e economias capitalistas no século XX demonstrou. No entanto, economias empresariais têm também um calcanhar de Aquiles. Elas liberam as energias dos empreendedores para perseguir seus objetivos de lucro e, com isso, promoverem a expansão da riqueza social. Esses mesmos empreendedores, porém, devem suportar as perdas que resultem dos erros de decisão que porventura cometerem. Frente à incerteza das demandas futuras, o empresário que for capaz de prever com sucesso a evolução das demandas dos clientes será bem recompensado, mas aqueles que não forem igualmente capazes (ou afortunados) pagarão o preço da perda e, talvez, da falência. No momento da decisão, o futuro é incerto, não há como saber quem será e quem não será bem sucedido. Aqueles indivíduos dotados de animal spirits se arriscarão em novos empreendimentos, mas os tímidos e cautelosos preferirão manter sua riqueza em formas mais seguras. Dentre essas formas mais seguras, está a detenção de ativos líquidos e, em especial, a moeda. É aqui que reside o problema da demanda efetiva, segundo Keynes. Os empresários que se arriscam, criam empregos e riquezas para a sociedade. Os que se defendem na demanda de ativos líquidos, contribuem para a redução do emprego e para a recessão econômica. Do mesmo modo, quando consumidores temerosos do futuro abstém-se de consumir, retendo moeda, eles contribuem para o mesmo problema. Quando se demanda ativos líquidos como a moeda, nega-se emprego aos trabalhadores que poderiam estar produzindo as outras formas de riqueza. Nos termos de Keynes, quando a demanda se volta para itens não-reprodutíveis (pelo emprego de trabalho) ao invés de bens e serviços, a demanda agregada se contrai e o desemprego se impõe. Se empresários esperam que a demanda futura será insuficiente para absorver sua produção, eles simplesmente não produzirão e os fatores de produção correspondentes ficarão desempregados. 
É neste quadro que se define a intervenção do Estado na visão de Keynes. Economias empresariais dependem da disposição de empresários de produzir (e investir). Esta disposição diminuirá sempre que houver razões para temer-se que a demanda agregada será insuficiente para absorver a produção ou quando o futuro se tornar excessivamente opaco para permitir que se faça previsões de demanda com algum grau de confiança. Nesse caso, ao invés de converter seus recursos monetários em fatores de produção, eles preferirão retê-los na forma de moeda. O temor da demanda futura reduzida reduz o emprego no presente e os empresários verão suas piores expectativas confirmadas. De acordo com Keynes, isto ocorre porque se trata de uma economia monetária: uma economia em que a moeda é uma forma de riqueza, alternativa a outros ativos, inclusive bens de capital e fatores de produção. Quando o rendimento esperado destes últimos não for adequado ou for muito incerto, muitos empresários buscarão refúgio na acumulação de dinheiro, e o emprego e o nível de atividades declinarão.

É neste sentido que o problema do capitalismo, segundo Keynes, não é a alocação, mas a mobilização de recursos. Aquela parcela dos fatores de produção que for empregada, pode estar sendo empregada da melhor forma possível. É com os fatores ociosos que se preocupou Keynes. A política econômica keynesiana não é uma política alocativa, mas uma política de mobilização, uma política macroeconômica, portanto, visando a administrar a demanda agregada de modo a mantêla no nível adequado à sustentação do pleno emprego. Idealmente, a política econômica keynesiana seria aquela que estimularia empresários a utilizar os fatores de produção disponíveis, deixando inteiramente a seu cargo a decisão de onde empregá-los. ${ }^{7}$

Grosso modo, as políticas de administração de demanda seriam duas: a política monetária, por onde os agentes econômicos são induzidos a ajustar suas demandas por movimentos de preços relativos dos ativos (taxas de juros); e a política fiscal, em que o governo age sobre a demanda diretamente através de seus gastos, ou indiretamente, através da imposição de tributos sobre os agentes privados. Segundo a teoria keynesiana, a política monetária tende a ter efeitos maiores sobre a decisão de investir, porque os movimentos das taxas de juros resultantes da ação de política monetária afetam principalmente os mercados de ativos, inclusive os de ativos reais, como equipamentos

7 Ressalvando a necessidade de enfrentar os casos de falha de mercado. Aqui, como sempre, Keynes é pragmático. Como escreveu a Marcus Fleming, em 1944, "[e]u não [Ihe] disse que você não deveria ter apego pelo sistema de preços (eu compartilho do seu apego). Eu disse que você não deveria ser iludido por ele." (CWJ MK, 26, p. 297). 
e construções. ${ }^{8}$ Já a política fiscal atuaria mais sobre as despesas de consumo, pois tanto o gasto público quanto os impostos incidiriam diretamente sobre a renda dos agentes econômicos, impactando suas despesas de consumo. ${ }^{9}$ A escolha de instrumentos (ou da combinação deles) deveria levar em conta, assim, as características de cada situação, que podem afetar a sensibilidade do comportamento privado aos estímulos de política, mas também os objetivos mais gerais da sociedade, que podem depender da ênfase diferenciada em investimentos ou em consumo.

\section{A 0 peração da Política Fiscal}

A política fiscal opera, como visto, seja induzindo variações no gasto privado (através de variações na renda disponível dos agentes econômicos resultantes de variações na imposição de tributos), seja através da complementação direta de gastos, através das despesas do governo. Assim, se, em face, por exemplo, de um clima de incerteza mais intensa, os agentes privados recuam de seus planos de dispêndio em consumo ou investimento, o governo pode compensar essa redução ampliando a sua própria demanda por bens e serviços, mantendo a demanda agregada inalterada e, com ela, os estímulos à manutenção do nível de emprego e de utilização de capacidade.

O impacto do gasto público sobre a demanda agregada e sobre o nível de atividades é semelhante, na teoria keynesiana, ao do gasto com investimentos privados. Cada real gasto pelo governo se transforma em renda para o agente privado que lhe fornece bens e serviços. Com sua renda aumentada pelo valor do gasto público, o agente privado amplia os seus próprios gastos de consumo, de acordo com sua propensão marginal a consumir, ${ }^{10}$ aumentando, deste modo, a renda daqueles que atendem à sua demanda de consumo. Também esses últimos consumirão parte da renda que receberam, poupando o restante, transmitindo o impulso de aumento de demanda para os seus

8 Em economias modernas com câmbio flutuante, a política monetária agiria também fortemente sobre as exportações liquidas em função de seu impacto sobre taxas de câmbio.

9 A preocupação com a combinação de políticas econômicas sempre esteve presente no pensamento Keynesiano. Richard Kahn temia que o uso de políticas fiscais expansivas contra recessões e de políticas monetárias contracionistas contra a inflação criaria um viés anti-investimento. Veja Kahn (1972, capítulo 7) e, também, Tobin (2003, capítulo 16, especialmente a página 127).

10 Isto é a proporção em que acréscimos de renda se convertem em acréscimos de gastos de consumo. Essa proporção é menor do que a unidade, dado que o consumidor reserva parte de seu acréscimo de renda para uso futuro, ou, em outras palavras, poupa parte de seu acréscimo de renda. 
próprios fornecedores. Este processo pelo qual a despesa inicial, no caso o gasto público, induz gastos de consumo adicionais é o que Keynes chamou na GT de multiplicador. ${ }^{11}$

Como um gasto original do setor público induz uma série de gastos adicionais em consumo, em face de uma deficiência de demanda agregada o gasto público necessário para alcançar ou manter o pleno emprego será inferior à deficiência observada, já que se poderá contar também com um aumento da demanda de consumo. ${ }^{12}$

Note-se que a política fiscal é definida pela fixação de um nível adequado de gastos públicos, não de déficit público. Na verdade, não há qualquer necessidade de que esses gastos não possam ser financiados por impostos, evitando o surgimento de déficits fiscais. Dada a sensibilidade da receita de impostos a variações da renda, já que a imensa maioria dos impostos em uma economia moderna são direta ou indiretamente proporcionais ao nível de renda, o aumento de gastos públicos induzirá aumentos também da receita de impostos. Note-se ainda que é perfeitamente possível que o total de impostos seja igual ao de gastos públicos, evitando o surgimento de qualquer déficit, mas nem por isso tornando a política ineficaz. ${ }^{13,14}$

Em condições excepcionalmente favoráveis, a política fiscal pode ser eficaz até mesmo por um efeito puramente informacional. Keynes contemplou a possibilidade de que o simples anúncio à sociedade de que o Estado estaria preparado para suprir qualquer deficiência

110 multiplicador é apenas o resultado do fato de que o gasto de um individuo em bens e serviços aumenta a renda do provedor desses mesmos bens e serviços, colocando este último em posição de reajustar seus próprios gastos de consumo, impactando, assim, a renda de um terceiro agente e assim sucessivamente. Note-se, porém, que o multiplicador não é infinito, porque a cada rodada o gasto passado à frente é menor que o recebido, já que cada agente poupa (isto é, deixa de demandar bens e serviços) parte da renda recebida.

12 Segundo Keynes, a teoria do consumo e do multiplicador, juntamente com a percepção do papel da incerteza na dinâmica de uma economia monetária, eram as principais inovações teóricas da GTI. Conforme CWJ MK, 14, p.109.

13 Dada a teoria do multiplicador, o gasto público é menor que o gap de demanda, mas a receita de impostos é proporcional à variação do gasto total (isto é, gasto público mais gastos de consumo induzido). Nada impede que o balanço entre gastos públicos e impostos se mostre equilibrado no final do processo, ou até mesmo superavitário, dependendo do valor do multiplicador e da sensibilidade da receita de impostos à variação da renda. Assim, em um quadro simplificado, se notarmos o multiplicador de renda por k, e a proporção da renda que se converte em impostos por a, teremos que $Y=k G$ e $T=a Y$, portanto $T=a k G$. Para $\mathrm{G}=\mathrm{T}$ é preciso que $a k=1$. Se, digamos, $\mathrm{k}=3$ e a participação dos impostos na renda for de $1 / 3$, o orçamento fiscal se equilibrará automaticamente, com a realização de G.

$14 \mathrm{~A}$ eficácia aqui referida também não depende da operação do teorema do orçamento equilibrado, de Haavelmo, pelo qual a realização de um gasto público igual a uma elevação de impostos de mesmo valor eleva a renda com um multiplicador igual à unidade. A elevação de impostos considerada no texto refere-se apenas à resultante da elevação da renda. 0 que se explora no texto são noções do que ficou conhecido como finanças funcionais. 
de demanda agregada pela mobilização de um pacote compensatório de investimentos públicos poderia ser suficiente para recuperar a expectativa favorável de empresários privados que os levasse a decidir recuperar o nível de produção e de investimentos consistente com o pleno emprego. Neste caso, paradoxalmente, a política fiscal ativista não se manifestaria em nenhum item concreto do orçamento público, operando diretamente sobre as expectativas dos empresários privados.

Keynes, porém, era suficientemente realista para assumir que este funcionamento ideal da política fiscal seria, de qualquer modo, relativamente improvável. Assim, sua atenção voltou-se para o impacto do gasto público realizado sobre a renda. Déficits públicos seriam, de fato, a solução de default quanto tudo o mais tivesse faIhado. ${ }^{15}$ Déficits fiscais só emergeriam em valor significativo se o gasto público por si falhasse em expandir o nível de atividades, como no caso de uma economia em depressão, por exemplo. Nessas circunstâncias, o déficit poderia resultar da combinação de um amplo programa de gasto público com um multiplicador relativamente reduzido (que pode ocorrer se os agentes privados estão assolados por tal incerteza sobre o futuro que não se animam sequer a gastar a proporção normal de sua renda acrescida pelo gasto público). Um gasto público elevado, com baixo multiplicador e baixa sensibilidade das receitas de impostos a variações da renda agregada (se, por exemplo, uma expansão dos gastos for acoplada a uma redução de impostos) poderia conduzir a um déficit público mais amplo. Este não seria um instrumento "normal" de política fiscal, contudo, mas o resultado do uso dessa política em condições especialmente adversas.

Como tudo na teoria keynesiana, a ordem dos eventos neste processo é de fundamental importância para entender sua natureza e potencialidades. ${ }^{16} \mathrm{~A}$ seqüência de eventos que permitiria à política fiscal ter o maior impacto expansivo possível sobre o nível de atividades seria a implementação de uma decisão de expansão de gastos

15 Sobre o papel do investimento publico na regularização do ciclo, conforme CWJ MK, 27, p. 122 e 322. Sobre o surgimento de um déficit fiscal como sinal de insuficiência da política, veja-se, no mesmo volume, p. 352-3.

16 Frequentemente, a oposição entre a abordagem keynesiana e a abordagem convencional neo-clássica é obscurecida pelo fato de que a especificação de condições de equilíbrio é muitas vezes semelhante entre elas. 0 caso da relação entre poupança e investimento é uma delas. A oposição se define pelos mecanismos que conduzem (ou não) as variáveis aos valores de equilíbrio, mais do que a descrição do estado terminal. 0 processo que liga investimento e poupança em Keynes é o mesmo que conecta gastos públicos à renda e à receita de impostos. É a concepção desse processo que opõe Keynes à ortodoxia, não a definição do equilíbrio. 
públicos financiada pela colocação no mercado de papéis de curto prazo de modo a aproveitar os saldos monetários ociosos mantidos pelo público como reserva de liquidez. Alternativamente, a colocação desses papéis poderia se iniciar pelo sistema bancário, oferecendo a esses trocar suas reservas monetárias por reservas secundárias, em papeis públicos de curto prazo, com reduzido impacto sobre as taxas de juros de curto prazo. ${ }^{17}$

Como no caso dos gastos de investidores privados, nesse estágio do processo de política fiscal, o que o Estado precisa é de meios de pagamento que lhe permitam implementar seu plano de gastos. Esse é um problema monetário, a ser resolvido no mercado monetário, nas linhas descritas no parágrafo anterior. É essencial, segundo Keynes, que não se recorra a aumentos de impostos nesta fase, porque eles deprimirão a renda antes que o gasto público possa ter tido a chance de exercer sua influência expansiva. Por razões similares, o Estado não deve buscar financiar seu gasto nesta fase pela colocação de papéis de longo prazo porque, não tendo ainda o nível de atividades se expandido, a renda ainda não terá crescido, nem, portanto, a poupança que deve resultar do acréscimo de renda estará disponível. Assim, não haverá ainda a demanda adicional por parte dos poupadores por papéis de longo prazo, que, se colocados no mercado, pressionarão as taxas de juros para cima, e causarão a redução (crowding out) de investimentos privados. Vê-se, assim, porque a seqüência de eventos é essencial na abordagem keynesiana: o processo de expansão da renda não é instantâneo e, por isso mesmo, não se pode contar em seu início com condições de financiamento do setor público que resultarão da conclusão do processo.

Quando o processo multiplicador tiver completado o essencial do ciclo de expansão secundária das despesas de consumo, e a renda tiver se expandido na medida prevista, haverá uma poupança adicional na economia de valor igual ao do gasto público que iniciou este ciclo. Parte dessa "poupança" existiria já sob a forma de aumento da receita de impostos resultantes da expansão da economia. Se esses recursos forem insuficientes para cobrir a despesa pública, haverá ainda nas mãos do setor privado poupança suficiente para absorver os títulos de longo prazo que o governo poderá agora colocar no mercado, sem pressionar a taxa de juros de longo prazo (e sem, portanto, prejudicar outras despesas dependentes dela, como os investimentos produtivos privados). Esse será o momento, portanto,

17 A decisão de recorrer ao mercado monetário para o financiamento inicial do gasto público mostra que a separação entre políticas fiscal e monetária é principalmente um artifício didático. 
da consolidação do passivo público, colocando-se papéis de longo prazo junto aos poupadores privados (que estarão demandando ativos no mercado no valor do acréscimo de sua poupança após pagos os impostos). Com a receita da colocação dos títulos públicos (e dos impostos recolhidos) o governo poderá saldar suas dívidas de curto prazo, recompondo sua capacidade para re-iniciar todo o processo caso fosse necessário.

Os familiarizados com a teoria de Keynes reconhecerão na descrição oferecida acima do processo de política fiscal uma analogia imediata com o problema do financiamento e da consolidação (finance e funding) de investimentos privados, que Keynes analisou em sua polêmica com Ohlin, no Economic J ournal em 1937. O reconhecimento é absolutamente correto. A analogia foi, na verdade, explorada pelo próprio Keynes ao discutir o financiamento dos gastos bélicos da Inglaterra durante a segunda guerra mundial. Embora não se tratasse de combater uma deficiência de demanda agregada, muito pelo contrário, Keynes se utiliza do mesmo esquema de financiamento e consolidação para discutir as formas adequadas de financiamento público que minimizassem os impactos do gasto público sobre a taxa de juros e, assim, sobre os investimentos privados. ${ }^{18}$

Em suma, a teoria keynesiana não propõe a irrelevância do equilíbrio fiscal. Ao contrário, Keynes preconizava uma política fiscal que, na sua forma mais benigna, prescindiria mesmo do próprio gasto público efetivo, caso as expectativas do setor privado respondessem favoravelmente ao anúncio da disposição (e da capacidade) do setor público de intervir caso a economia estivesse sub-utilizando seus recursos. Se esse efeito, digamos, psicológico, fosse insuficiente, os gastos deveriam realmente ser realizados, mas de modo a minimizar seus impactos colaterais sobre a economia, especialmente sobre a taxa de juros, caso formas inadequadas de financiamento fossem adotadas. Seguindo-se a seqüência implícita no modelo de determinação da renda agregada proposto por Keynes, o orçamento poderia ser equilibrado ao final da expansão do nível de atividades, ou financiado pela colocação de títulos de longo prazo no momento em que isto já não pudesse mais perturbar o mercado de capitais.

\section{Dificuldades e Limitações}

A operação da política fiscal como descrita na seção anterior se apóia na validade de certas premissas que devem ser explicitadas, porque a sua ausência pode comprometer a eficácia da política como

18 Conforme CWJ MK, 22, pp. 158. 
instrumento de administração de demanda agregada. Essas premissas referem-se a: (i) o estado de expectativas dos agentes privados; (ii) o grau de utilização da capacidade produtiva; e (iii) o estado dos mercados de capitais.

À época em que Keynes escreveu a GT pouco se poderia assumir quanto às expectativas do público em relação à eficácia da política fiscal. De fato, o tamanho do Estado, em termos de participação na renda nacional, não lhe dava qualquer possibilidade de influir de forma mais decisiva na vida econômica. Apenas durante guerras o Estado assumia dimensões mais significativas como comprador de bens e serviços ou como coletor de impostos. Assim, Keynes poderia assumir expectativas praticamente neutras em relação ao ativismo fiscal. $\mathrm{Na}$ ausência de experiências mais duradouras de política fiscal e seus efeitos, não era despropositado assumir que as expectativas do público com relação ao seu impacto seriam muito dispersas.

A consideração das expectativas é muito importante para se evitar o mecanicismo característico do que veio a se chamar de keynesianismo hidráulico, em que a política econômica operaria como o mover de alavancas ou o apertar de botões em engenhos mecânicos. 0 impacto da política econômica se dá através dos comportamentos que induz, mas estes, por sua vez, dependem de como os agentes econômicos interpretam os estímulos recebidos. Se expectativas são muito dispersas, as reações serão variadas, de modo a dar aos estímulos experimentados de modo mais imediato um peso relativamente mais significativo na tomada de decisões. Assim, se não há experiência prévia com relação à ampliação do gasto público, pode-se esperar que o público reaja ao aumento de sua renda exatamente do modo esperado pela teoria do multiplicador.

Esta recepção benigna deve ser contrastada com o clima francamente adverso que se criou nos anos 80 , por exemplo. A experiência das décadas imediatamente anteriores, até pelo menos os anos 60 , foi, corretamente ou não, interpretada como indicando os malefícios criados pela irresponsabilidade fiscal. A geração de déficits fiscais foi responsabilizada pela emergência de intensas pressões inflacionárias cujo controle, através de políticas monetárias contracionistas, impôs pesados custos às sociedades que sofreram o problema. Em grande parte, as expectativas a respeito da política fiscal passaram a ser regidas pela convenção de que governos eram intrinsecamente irresponsáveis, incapazes de controlar seus gastos e evitar déficits fiscais geradores de pressões inflacionárias. As expectativas formadas nesse ambiente seriam as de que o desequilíbrio fiscal do presente fatalmente implicaria a austeridade monetária de amanhã, com elevação de juros e desaquecimento da economia. Nessas circunstâncias, com padrões 
de expectativas tão adversos, a política fiscal perde eficácia. O gasto público, ao invés de induzir a expansão dos gastos privados, pode acabar induzindo a formação de uma poupança precaucionária por parte dos atentes privados, temerosos da recessão que a autoridade monetária fatalmente teria que gerar em seguida.

Assim, o primeiro condicionante a ser considerado na formulação da política fiscal é o estado de expectativas dos agentes privados. Se o gasto é realizado em ambiente marcado pela expectativa de que o governo é propenso a gerar déficits permanentes, sua eficácia poderá diminuir drasticamente pela antecipação de elevações das taxas de juros que induzirá, modificando de forma perversa os preços dos ativos, inclusive os ativos reais. A preocupação com o equilíbrio fiscal, assim, pode ser instrumental para permitir que a política fiscal tenha efeitos positivos, quando for necessária. ${ }^{19}$

A segunda condição é provavelmente mais familiar, por ser explorada mesmo pelo keynesianismo mais convencional. A política fiscal keynesiana é um instrumento de regularização da demanda agregada de modo a sustentar o pleno emprego. Assim, ela não deve ser ativada se a economia já estiver em pleno emprego, porque nessas circunstâncias a soma das demandas privadas e pública ultrapassará a capacidade produtiva do país e pressões inflacionárias realmente emergirão. ${ }^{20}$

Esta condição pode parecer óbvia, mas envolve algumas dificuldades importantes quando se lembra que gastos públicos não servem apenas como reguladores de demanda agregada. De fato, o Estado deve efetuar gastos primariamente para ofertar bens públicos, como segurança pública e nacional, educação, saúde, etc. A oferta de bens públicos deve ser permanente, havendo, portanto, níveis de despesa que são relativamente fixos, independentes do nível de atividades da economia. Em paralelo a essas despesas estão aquelas voltadas, primariamente, para a regularização da demanda agregada.

A consideração desses dois deveres do Estado, prover permanentemente bens públicos e regularizar, quando necessário, a demanda agregada, exige que a política de gastos seja abordada de forma mais flexível, para evitar que os dois objetivos entrem em conflito. A saída proposta por Keynes passava pela elaboração de dois orçamentos fiscais, o de gastos correntes e o de gastos de capital. 0

19 Ao que indicam as evidências, este teria sido o caso da Irlanda e Dinamarca recentemente.

20 Excetuando-se naturalmente as situações excepcionais onde a política fiscal não está subordinada à manutenção do pleno emprego mas visa a acomodação de demandas do Estado, como se dá durante períodos de conflito bélico. Keynes examinou esta última situação em seu famoso panfleto How to Pay for the War, CWJ MK, 9. 
primeiro cobriria as despesas rígidas, inadiáveis do governo, destinadas a garantir a oferta de bens públicos na medida necessária. 0 orçamento corrente, segundo Keynes, teria de estar equilibrado todo o tempo. Já o orçamento de capital seria ativado quando a demanda agregada se afastasse do nível de pleno emprego, acima ou abaixo desse nível. ${ }^{21}$

A separação entre os dois orçamentos se destinaria precisamente a separar aquelas funções de Estado que não podem ser adiadas ou suprimidas, nem mesmo temporariamente, daquelas cuja função seria anti-cíclica. Ao exigir que o orçamento corrente estivesse equilibrado todo o tempo, o que Keynes busca é exatamente neutralizar estes gastos como fonte de pressão de demanda quando a economia já estivesse em seu limite de pleno emprego. Neste caso, a rigor, a política fiscal como instrumento de administração de demanda seria confinada ao orçamento de capital que, por sua natureza discricionária, poderia ter o seu ritmo de implementação variado conforme a conjuntura.

0 debate em torno dessa proposta afastou-se freqüentemente do seu alvo. Muitos discutiram até onde seria possível separar-se gastos correntes de gastos de capital, levando o debate para um campo conceitual inadequado para solucionar um problema de natureza inteiramente prática. $\mathrm{Na}$ verdade, o que Keynes busca ao propor a elaboração de dois orçamentos é a separação entre o cumprimento das funções rotineiras do Estado e a realização de seus gastos discricionários. A diferenciação que importa reside na possibilidade de adiamento dos gastos de forma a contra-restar as forças cíclicas da economia. Economias menos desenvolvidas, onde um certo nível de investimento público obedece a demandas permanentes, poderiam incluir esses investimentos no orçamento de rotina, e prover suas fontes de financiamento de modo a evitar déficits em qualquer período. Por outro lado, a criação de instrumentos como os estabilizadores endógenos pode agilizar a entrada em operação de gastos anti-cíclicos. ${ }^{22}$

\section{Conforme CWJ MK, 27, p. 225.}

22 Uma variante da distinção proposta por Keynes foi a contraposição entre o orçamento de pleno emprego e o orçamento corrente, pelos economistas keynesianos do Conselho de Assessores Econômicos do Presidente Kennedy. 0 orçamento de pleno emprego, como 0 orçamento corrente de Keynes, deveria estar sempre equilibrado precisamente para evitar que a demanda agregada ultrapassasse o nível de renda de pleno emprego. Já o orçamento corrente variaria com o ciclo, sendo deficitário quando houvesse desemprego involuntário e equilibrado ou superavitário quando os níveis de desemprego se aproximassem do pleno emprego. Note-se que o termo corrente tem um significado completamente diferente aqui do que tem no uso feito por Keynes. Veja, para tanto, Tobin e Weidenbaum (1988, parte 1). 
Finalmente, há o problema da consolidação (funding) da dívida pública em caso de surgimento de déficits fiscais, isto é, da colocação de títulos de dívida de longo prazo no mercado. Como já visto, a teoria do multiplicador garante que a demanda total por ativos correspondente à poupança gerada pelo gasto público que permanecesse a descoberto (isto é, descontado o aumento de impostos causado pelo próprio gasto público) seria exatamente igual ao valor dos títulos a serem colocados no mercado pelo Tesouro. 0 que a teoria do multiplicador não garante, porém, é que esses poupadores queiram adquirir precisamente os papéis emitidos pelo Tesouro. Esses poupadores podem, por exemplo, exibir forte preferência pela liquidez e preferir reter moeda. Alternativamente, eles podem decidir reter outras classes de ativos por razões, por exemplo, de diversificação de carteiras.

$\mathrm{Na}$ medida em que o mercado resista a absorver o acréscimo de títulos públicos em uma função de uma preferência pela liquidez, a existência de intermediários financeiros pode, até certo ponto, resolver o problema. Bancos, por exemplo, podem absorver esses títulos, com recursos colhidos pela aceitação de depósitos a prazo ou de poupança, por exemplo. Esta solução, naturalmente, também enfrenta limites, especialmente na necessidade de instituições financeiras manterem, elas próprias, algum grau de diversificação de suas carteiras de ativos. Esta busca de diversificação pode ser característica da demanda mais geral por ativos por parte do público, impondo, pelo lado do financiamento, também limites à política fiscal.

\section{Considerações Finais}

A política econômica keynesiana instrumentaliza a necessidade de regulação da demanda agregada de modo a manter a economia em níveis de atividade tão próximos do pleno emprego quanto a sociedade deseje. Assim, a política fiscal não consiste necessariamente em manter gastos públicos elevados, nem, muito menos, em manter déficits fiscais faça chuva ou faça sol. Déficits permanentes (ou estruturais, como chamariam alguns) são causas de desequilíbrio na economia, tanto quanto a deficiência de algum componente da demanda privada. Os desequilíbrios serão tanto de natureza "real", para usar a velha dicotomia dos modelos macroeconômicos convencionais, entre demanda agregada excessiva e capacidade produtiva, quanto financeiros, entre colocação de títulos de dívida pública e demandas privadas por ativos mais diversificados. Em condições modernas, há ainda que se considerar o impacto de uma política 
fiscal desregrada sobre expectativas, que pode engendrar um mecanismo perverso, pelo qual a expansão fiscal acabe mesmo por levar a uma contração da economia.

0 ativismo fiscal e monetário de Keynes nada tem de irresponsável. Na verdade, como os memorandos escritos por ele ao Tesouro britânico durante a guerra demonstram, Keynes insistiu na necessidade de se planejar cuidadosamente a política fiscal como um processo, de modo precisamente a evitar a emergência de desequilíbrios que prejudicassem a operação da economia. De qualquer forma, a política fiscal proposta por Keynes se desenhava em termos de gastos públicos, não de déficits fiscais. Estes eram instrumentos de último recurso, a serem utilizados se e quando os mecanismos mais adequados falhassem na sustentação da demanda agregada.

Mas o cuidado com a geração de déficits fiscais não é a única, nem talvez a mais importante das lições propostas por Keynes. A teoria do multiplicador mostrava que o equilíbrio fiscal é um objetivo meritório mas mais factível quando a economia se expande. Se a economia não estiver em pleno emprego, o equilíbrio fiscal deve ser buscado de modo a promover a expansão da economia. Paradoxalmente, o equilíbrio fiscal pode ser obtido quando os gastos públicos se expandem, se isto levar a um crescimento da renda que resulte no crescimento necessário da receita de impostos. A busca do equilíbrio fiscal pelo aumento dos impostos, ou pelo corte de gastos, quando a economia já se encontra abaixo do pleno emprego pode acabar sendo desastroso, como as muitas experiências de ajuste fiscal patrocinadas pelo $\mathrm{FMI}$ ao longo dos anos mostraram. O corte de gastos numa economia com desemprego leva à contração da renda e, com ela, a redução das receitas de impostos, forçando novos cortes de gastos, numa espiral descendente até o ponto em que um equilíbrio seja eventualmente encontrado a níveis de renda inaceitavelmente baixos. Numa economia empresarial, é preciso manter a demanda atraente para que empresários decidam produzir, e com isso expandir a renda e pagar impostos. 0 único equilíbrio fiscal sustentável é aquele que se atinge quando a economia utiliza plenamente seus recursos.

\section{Referências Bibliográficas}

CARVALHO, F.C. Mr Keynes and the Post Keynesians. Cheltenham: Edward Elgar, 1992.

Economic Policies for Monetary Economies. Keynes's Economic Policy Proposals for an Unemployment-free Economy. Revista de Economia Política, v. 17, n. 4, p. 31-51, out/dez 1997. 
. Keynes como reformador social. In: FERRARI FILHO, F. (org). Teoria Geral Setenta Anos Depois: Ensaios sobre Keynes e Teoria Pós Keynesiana. Porto Alegre: Editora da UFRGS, 2006.

DAVIDSON, P. M oney and the Real World. Londres: Macmillan, 1972.

KAHN, R. Selected Essays on Employment and Growth. Cambridge: Cambridge University Press, 1972.

KEYNES, J .M. The Economic Consequences of the Peace. Londres: Macmillan, 1920.

. The General Theory of Employment, Interest and M oney. New York: Harcourt, Brace, J ovanovitch, 1964.

LEIJ ONHUFVUD, A. On Keynesian Economics and the Economics of Keynes. N ew York: Oxford University Press, 1968.

MOGGRIDGE, D.; J OHNSON, E. (orgs.). The Collected W ritings of J ohn M aynard Keynes. Londres: Macmillan para a Royal Economic Society, 1971 a 1982 (identificados pela sigla CWJ MK, seguida pelo número do volume em arábico).

TOBIN , J . Policies for Prosperity. Essays in a Keynesian Mode. Cambridge: MIT Press, 1987. . World Finance and Economic Stability. Selected Essays of J ames Tobin. Cheitenham: Edward Elgar, 2003.

TOBIN, J .; W EIDENBAUM, M. (orgs.). Two Revolutions in Economic Policy. Cambridge: MIT Press, 1988.

TURE, N. Keynes's influence on public policy: a conservative's view. In: W ATTEL, H. (org.). The Policy Consequences of J ohn Maynard Keynes. Armonk: M.E. Sharpe, 1985. 
